\title{
Off-pump technique reduces surgical mortality after elective coronary artery bypass grafting in patients with preoperative renal failure
}

Chikara Ueki, MD, ${ }^{\mathrm{a}}$ Hiroaki Miyata, $\mathrm{PhD},{ }^{\mathrm{b}}$ Noboru Motomura, MD, PhD, ${ }^{\mathrm{c}}$ Ryuzo Sakata, MD, PhD, ${ }^{\mathrm{d}}$ Genichi Sakaguchi, MD, PhD, ${ }^{a}$ Takehide Akimoto, $\mathrm{MD}, \mathrm{PhD},{ }^{\mathrm{a}}$ and Shinichi Takamoto, $\mathrm{MD}, \mathrm{PhD},{ }^{\mathrm{e}}$ for the Japan Cardiovascular Surgery Database

\section{ABSTRACT}

Objectives: Most randomized controlled trials of off-pump versus on-pump coronary artery bypass grafting (CABG) have included limited numbers of patients with preoperative renal failure. This study was performed to evaluate the association between the clinical benefit of the off-pump technique and chronic kidney disease stage.

Methods: We analyzed 38,051 patients with chronic kidney disease who underwent primary nonemergent isolated CABG from 2013 to 2015 as reported in the Japan Cardiovascular Surgery Database-Adult section. These patients were stratified into 4 categories according to their estimated glomerular filtration rate (eGFR) of 60 to 90,30 to 59 , and $<30 \mathrm{~mL} / \mathrm{min} / 1.73 \mathrm{~m}^{2}$, and hemodialysisdependent. The clinical outcomes were compared between patients undergoing off-pump and on-pump CABG in each stratum using inverse probability of treatment weighting.

Results: In total, 23,634 (62.1\%) patients were intended for off-pump CABG. In patients with mildly reduced renal function (eGFR $60-89 \mathrm{~mL} / \mathrm{min} / 1.73 \mathrm{~m}^{2}$ ), there was no significant risk reduction effect of off-pump CABG for surgical mortality. Conversely, in patients with moderate or severe renal disease (eGFR $<60 \mathrm{~mL} / \mathrm{min} /$ $1.73 \mathrm{~m}^{2}$ ), off-pump CABG was associated with a significantly lower incidence of surgical death (odds ratio with $95 \%$ confidence interval: eGFR $30-59 \mathrm{~mL} / \mathrm{min} /$ $1.73 \mathrm{~m}^{2}, 0.66$ [0.51-0.84]; eGFR $<30 \mathrm{~mL} / \mathrm{min} / 1.73 \mathrm{~m}^{2}, 0.51$ [0.37-0.72]; and hemodialysis-dependent, 0.68 [0.51-0.90]). In addition, in patients with severe renal disease (eGFR of $<30$ ), off-pump CABG was associated with a significantly lower incidence of de novo dialysis.

Conclusions: The off-pump technique significantly reduced surgical mortality in patients with moderate or severe preoperative renal dysfunction. (J Thorac Cardiovasc Surg 2018;156:976-83)

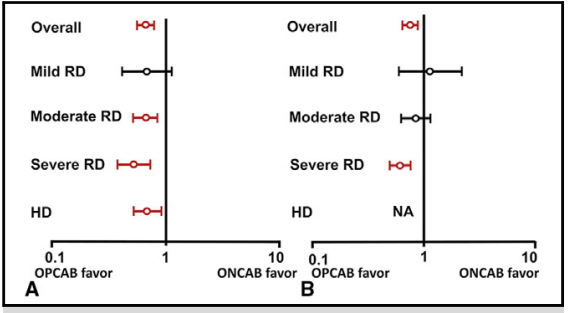

Propensity score-adjusted odds ratio for (A) surgical mortality and (B) de novo dialysis.

\section{Central Message}

The off-pump technique improves early mortality in patients with moderate or severe preoperative renal dysfunction.

\section{Perspective}

The association between the benefit of the offpump technique and preoperative renal function remains unclear. In this large retrospective study, the mortality benefit of the off-pump technique was manifested in patients with moderate or severe renal dysfunction. This finding will help to identify patients who would benefit from the off-pump technique.

See Editorial Commentary page 984.

See Editorial page 974.
From the ${ }^{a}$ Department of Cardiovascular Surgery, Shizuoka General Hospital, Shizuoka, Japan; ${ }^{\mathrm{b}}$ Department of Health Policy and Management, Keio University, Tokyo, Japan; 'Department of Cardiovascular Surgery, Toho University, Sakura Medical Center, Sakura, Japan; ${ }^{\mathrm{d}}$ Department of Cardiovascular Surgery, Kobe City Medical Center General Hospital, Kobe, Japan; and ${ }^{\mathrm{e}}$ Mitsui Memorial Hospital, Tokyo, Japan.

Read at the 97th Annual Meeting of The American Association for Thoracic Surgery, Boston, Massachusetts, April 29-May 3, 2017.

Received for publication April 30, 2017; revisions received Jan 3, 2018; accepted for publication March 2, 2018; available ahead of print May 9, 2018.

Address for reprints: Chikara Ueki, MD, Department of Cardiovascular Surgery, Shizuoka General Hospital, 4-27-1 Kita-Ando Aoi-ku, Shizuoka 420-8527, Japan (E-mail: uekichikara@gmail.com).

0022-5223/\$36.00

Copyright (c) 2018 by The American Association for Thoracic Surgery

https://doi.org/10.1016/j.jtcvs.2018.03.145
Preoperative renal disease is a well known risk factor for adverse events after coronary artery bypass grafting $(\mathrm{CABG}) .{ }^{1,2} \mathrm{~A}$ report from the Society of Thoracic

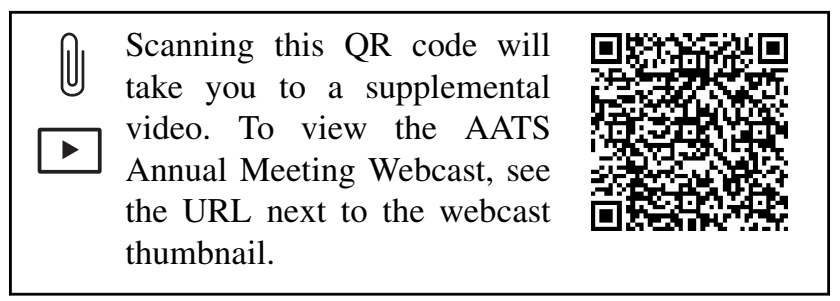




\section{Abbreviations and Acronyms \\ $\mathrm{CABG}=$ coronary artery bypass grafting \\ $\mathrm{CKD}=$ chronic kidney disease \\ eGFR = estimated glomerular filtration rate \\ GFR = glomerular filtration rate \\ IPTW $=$ inverse probability of treatment weighting \\ JCVSD = Japan Cardiovascular Surgery Database \\ $\mathrm{ONCAB}=$ on-pump coronary artery bypass grafting \\ $\mathrm{OPCAB}=$ off-pump coronary artery bypass grafting \\ PCI = percutaneous coronary intervention \\ STS = Society of Thoracic Surgeons}

Surgeons (STS) national database stated that preoperative renal disease is common in patients who undergo CABG and that early mortality and morbidity after $\mathrm{CABG}$ rise inversely with declining preoperative renal function. ${ }^{3}$

Previous meta-analyses of randomized trials comparing off-pump CABG (OPCAB) and on-pump CABG (ONCAB) have failed to show the mortality benefit of OPCAB..$^{4-6}$ However, it has also been shown that the mortality benefit of OPCAB is significantly related to the risk profile of the enrolled patients. ${ }^{4}$ In addition, multiple retrospective studies have shown the mortality benefit of OPCAB in high-risk patient cohorts (Video 1). ${ }^{7-9}$ Therefore, it can be hypothesized that OPCAB is associated with a mortality benefit in patients with preoperative renal dysfunction. Most randomized trials have included limited numbers of patients with preoperative renal disease. ${ }^{5}$ For example, a recent large randomized trial, the Randomized On/Off Bypass (ROOBY) trial, included only a small number of patients with an elevated serum creatinine concentration $(8.5 \%$ in the OPCAB group and $7.2 \%$ in the ONCAB group). ${ }^{10}$ Another recent large randomized trial, the CABG Off or On Pump Revascularization Study (CORONARY), also included only a limited number of dialysis patients $(1.7 \%$ in the OPCAB group and $1.1 \%$ in the ONCAB group). ${ }^{11}$ Consequently, most randomized trials could not evaluate the clinical benefit of OPCAB in patients with preoperative renal disease. A risk-adjusted retrospective study using a large data set is therefore needed to understand the association between the benefit of OPCAB and preoperative renal disease. This study was performed to determine the association between the clinical benefit of OPCAB and preoperative chronic kidney disease (CKD) stage using data from the Japan Cardiovascular Surgery Database (JCVSD).

\section{METHODS}

\section{The JCVSD}

The JCVSD was established in 2000 to evaluate surgical outcomes after cardiovascular procedures in hospitals throughout Japan. As of 2014, the

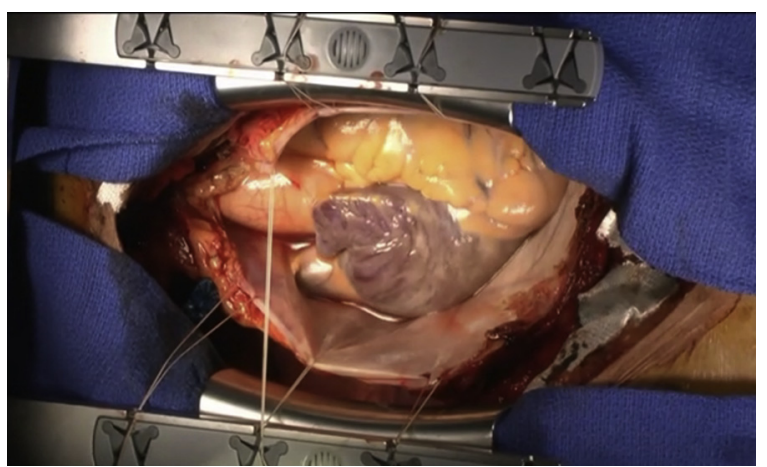

VIDEO 1. Off-pump coronary artery bypass grafting with skeletonized bilateral internal thoracic arteries for a patient with left main coronary disease. Video available at: https://www.jtcvs.org/article/S0022-5223(18) 30934-6/fulltext.

JCVSD-Adult section had collected clinical information from more than 538 hospitals across Japan. More than 300 variables in the data collection form are nearly identical to those of the STS National Database. The content of the JCVSD-Adult section is available online at http://www.jacvsd.umin jp. The methods of data collection from the JCVSD have been previously described. ${ }^{1}$ The institutional review board at each participating hospital has approved the collection of their data for use in the JCVSD, and the Data Utilization Committee of the JCVSD approved the use of data for the present study. To date, data collection has achieved a high level of completion, with less than $3 \%$ of entries missing for overall preoperative risk factors used in risk models. In addition, the accuracy of submitted data is maintained by regular data auditing in which monthly visits are made to participating hospitals to check the reported data against clinical records. Data validity is further confirmed by independent comparison of specific hospitals' volume of cardiac surgeries entered in the JCVSD with that reported in the annual survey of the Japanese Association for Thoracic Surgery. ${ }^{12}$ Further, from 2010 onward, the JCVSD served as part of the National Clinical Database in Japan, which includes clinician-initiated databases reflecting all surgical fields. By the end of 2013, the JCVSD had become a national database covering almost all cardiac procedures in Japan.

\section{Study Population}

The data of patients included in the JCVSD-Adult section from January 1, 2013, to December 31, 2015, were analyzed. Patients with complete data on preoperative renal function who underwent primary nonemergent isolated CABG were included. The exclusion criteria were an emergent or salvage status, redo surgery, and preoperative cardiogenic shock. Records with missing data on age (or out-of-range age), sex, or 30-day status (see "Study End Points" for an explanation) were excluded. With the exception of the body surface area and preoperative creatinine concentration, all missing or out-of-range values were imputed using the variable-specific median value. Upon completion of this data cleaning procedure, 38,804 patients were detected. After excluding 753 patients with normal renal function (estimated glomerular filtration rate [eGFR] of $\geq 90 \mathrm{~mL} / \mathrm{min} / 1.73 \mathrm{~m}^{2}$ ), 38,051 patients with $C K D$ were included in the present study. These patients were stratified into 4 groups according to their most recently available preoperative eGFR, which was calculated from the Modification of Diet in Renal Disease equation: eGFR $\mathrm{mL} / \mathrm{min} / 1.73 \mathrm{~m}^{2}=194 \times$ (serum creatinine level $[\mathrm{mg} / \mathrm{dL}])^{-1.094} \times(\text { age [years] })^{-0.287} \times 0.739$ (if female).$^{13}$ On the basis of the result, the patients were determined to have mild renal disease (eGFR $\left.=60-90 \mathrm{~mL} / \mathrm{min} / 1.73 \mathrm{~m}^{2} ; \mathrm{n}=7260\right)$, moderate renal disease $\left(\right.$ eGFR $\left.=30-59 \mathrm{~mL} / \mathrm{min} / 1.73 \mathrm{~m}^{2} ; \mathrm{n}=22,727\right)$, severe renal disease (eGFR $<30 \mathrm{~mL} / \mathrm{min} / 1.73 \mathrm{~m}^{2} ; \mathrm{n}=4098$ ), or hemodialysis dependence $(\mathrm{n}=3966)$. Because an intention-to-treat principle was applied to all statistical analyses, patients intended for OPCAB were included in the OPCAB group even if they were converted intraoperatively to $\mathrm{ONCAB}$ and vice versa. 


\section{Study End Points}

The study end points were surgical mortality, postoperative renal failure with newly required dialysis, and a composite outcome consisting of surgical mortality and major morbidity. Surgical mortality was defined as death within 30 days after surgery and death during the index hospitalization. Major morbidity was defined as any of the following postoperative complications during hospitalization or within 30 days postoperatively: stroke, reoperation for bleeding, mechanical ventilation required for $>24$ hours postoperatively, renal failure with newly required dialysis, or deep sternal wound infection.

\section{Statistical Analysis}

Continuous variables are expressed as mean $\pm \mathrm{SD}$, and the unpaired $t$ test or Wilcoxon rank sum test was used for comparisons. Categorical variables are expressed as percentages and were compared using the $\chi^{2}$ test. Two risk-adjustment methods were used to adjust for differences in baseline characteristics because the patients were not randomly assigned to receive either ONCAB or OPCAB. First, the risk-adjusted effect of OPCAB on each clinical outcome was estimated within a simultaneous multivariable logistic regression model that included 29 preoperative variables: age, sex, body mass index, presence of unstable angina, peripheral vascular disease, cerebrovascular disease (presence of stroke or a history of transient ischemic attack), hypertension, hyperlipidemia, diabetes, smoking history, chronic lung disease (mild, moderate, or severe), immunosuppressive therapy, arrhythmia, preoperative intra-aortic balloon pump counterpulsation, preoperative inotropic agents, grade $\geq 1$ aortic stenosis, grade $\geq 2$ aortic regurgitation, grade $\geq 1$ mitral stenosis, grade $\geq 2$ mitral regurgitation, grade $\geq 2$ tricuspid regurgitation, previous percutaneous coronary intervention (PCI), history of myocardial infarction, left ventricular dysfunction (left ventricular ejection fraction of $<30 \%$ ), congestive heart failure, New York Heart Association class III or IV, triple-vessel disease, left main coronary artery disease, urgent surgery, and hospital annual CABG volume. All of these variables except hospital annual $\mathrm{CABG}$ volume are the known risk factors comprising the STS risk model for isolated $\mathrm{CABG}^{2}{ }^{2}$ Second, inverse probability of treatment weighting (IPTW) was performed to verify the estimated prognostic effect. ${ }^{14}$ Each patient's estimated propensity score (the probability of being intended to undergo OPCAB) was calculated in a simultaneous multivariable logistic regression model including the 29 previously mentioned preoperative variables as covariates. Propensity scores were created within the whole cohort and each of the 4 renal disease categories (c-statistic with $95 \%$ confidence interval: whole cohort, 0.588 [0.583-0.594]; mild renal disease, 0.628 [0.615-0.641]; moderate renal disease, 0.632 [0.625-0.639]; severe renal disease, 0.642 [0.624-0.659]; hemodialysis dependence, 0.633 [0.616-0.651]). The inverse probability weights calculated using the propensity score were applied to a logistic regression model to obtain the propensity-weighted odds ratio of OPCAB. The same propensity scores were used for every outcome. All reported $P$ values are 2 -sided, and $P<.05$ was considered statistically significant. Statistical analysis was performed using SPSS version 20.0 (IBM Corp, Armonk, NY).

\section{RESULTS \\ Patient Characteristics and Surgical Data}

Among the 38,051 patients analyzed, 23,634 (62.1\%) were planned for OPCAB. Among these patients, unplanned conversion from $\mathrm{OPCAB}$ to $\mathrm{ONCAB}$ occurred in 734 patients $(3.1 \%)$. The patient characteristics in the overall cohort are presented in Table 1. Patients in the OPCAB group were significantly older and had more comorbidities such as cerebrovascular disease, chronic lung disease, peripheral vascular disease, a history of PCI, and aortic valve insufficiency. The ONCAB group contained significantly more patients with diabetes and had a significantly higher prevalence of previous myocardial infarction, left ventricular dysfunction, unstable angina, congestive heart failure, New York Heart Association class III or IV, left main coronary artery disease, and triple-vessel disease. Moderate to severe renal disease (eGFR $<60 \mathrm{~mL} / \mathrm{min} / 1.73 \mathrm{~m}^{2}$ ) was observed in most patients $(79.1 \%$ in the ONCAB group, $79.5 \%$ in the OPCAB group). Although the preoperative eGFR was slightly lower in the OPCAB than ONCAB group, the distribution of renal disease stages was almost identical between the 2 groups.

As shown in Table 2, the surgical duration was significantly shorter in the $\mathrm{OPCAB}$ than $\mathrm{ONCAB}$ group (307.3 vs 354.7 minutes, respectively). In the ONCAB group, cardioplegic heart arrest was used in 8190 patients $(56.8 \%)$, and cold blood cardioplegia was used in most of these patients. The number of distal anastomoses was significantly lower in the OPCAB than ONCAB group (3.02 vs 3.17 , respectively).

\section{Clinical Outcomes}

Surgical mortality. In the whole cohort, the surgical mortality rate was significantly lower in the OPCAB than ONCAB group $(1.5 \%$ vs $2.4 \%$, respectively; $P<.001)$. When stratified according to preoperative renal function, worsening preoperative renal dysfunction was associated with increasing surgical mortality (Table 3).

Although the risk reduction effect of OPCAB was not statistically significant in the mild renal disease group, the risk reduction effect of OPCAB was significant in patients with moderate or severe renal disease (Tables 3 and 4). The risk adjustment in the multivariable logistic regression model as well as the IPTW analyses confirmed these results (Table 4).

Renal failure with newly required dialysis. In the whole cohort, the incidence of newly required dialysis was significantly lower in the $\mathrm{OPCAB}$ than $\mathrm{ONCAB}$ group $(1.5 \%$ vs $2.1 \%$, respectively; $P<.001)$. In patients with normal renal function or mild to moderate renal disease, the incidence of newly required dialysis was $\leq 1 \%$. Conversely, in patients with severe renal disease, the incidence of newly required dialysis was quite high $(12.9 \%$ in the ONCAB group, $7.8 \%$ in the OPCAB group; Table 3).

The renoprotective effect of OPCAB was significant in patients with severe renal disease (Tables 3 and 4). The risk adjustment in the multivariable logistic regression model as well as the IPTW analyses confirmed these results (Table 4).

Composite outcome. In the whole cohort, the incidence of the composite outcome was significantly lower in the 
TABLE 1. Patient characteristics

\begin{tabular}{|c|c|c|c|c|}
\hline Variable & $\%$ Missing & ONCAB $(n=14,417)$ & OPCAB $(n=23,634)$ & $P$ value \\
\hline Age, $y$ & 0.0 & $68.5 \pm 10.0$ & $69.8 \pm 9.7$ & .001 \\
\hline Male sex & 0.0 & $11,636(80.7)$ & $18,976(80.3)$ & .249 \\
\hline Body mass index & 0.0 & $23.8 \pm 3.7$ & $23.7 \pm 3.5$ & $<.001$ \\
\hline Smoking history & 0.0 & $7696(53.4)$ & $12,541(53.0)$ & .427 \\
\hline Diabetes & 0.0 & $8066(55.9)$ & $12,526(53.0)$ & $<.001$ \\
\hline Hyperlipidemia & 0.0 & $9221(64.0)$ & $15,240(64.5)$ & .421 \\
\hline Hypertension & 0.0 & $11,220(77.8)$ & $18,670(79.0)$ & .004 \\
\hline Serum creatinine, $\mathrm{mg} / \mathrm{dL}$ & 0.0 & $1.70 \pm 2.33$ & $1.72 \pm 2.39$ & .246 \\
\hline $\begin{array}{l}\text { eGFR, } \mathrm{mL} / \mathrm{min} / 1.73 \mathrm{~m}^{2} \\
60 \text { to } 90 \text { (mild) } \\
30 \text { to } 59 \text { (moderate) } \\
<30 \text { (severe) }\end{array}$ & 0.0 & $\begin{array}{l}45.2 \pm 21.4 \\
2789(19.0) \\
8620(58.6) \\
1498(10.2)\end{array}$ & $\begin{array}{c}45.0 \pm 25.3 \\
4471(18.5) \\
14,107(58.5) \\
2600(10.8)\end{array}$ & $\begin{array}{l}.294 \\
.295 \\
.807 \\
.066\end{array}$ \\
\hline Preoperative dialysis & 0.0 & $1510(10.3)$ & $2456(10.2)$ & .788 \\
\hline Cerebrovascular disease & 0.0 & $1595(11.1)$ & $2956(12.5)$ & $<.001$ \\
\hline Chronic lung disease & 0.0 & $1730(12.0)$ & 3462 (14.6) & $<.001$ \\
\hline Peripheral vascular disease & 0.0 & $2303(16.0)$ & 4418 (18.7) & $<.001$ \\
\hline Previous PCI & 0.0 & $3376(23.4)$ & $6134(26.0)$ & $<.001$ \\
\hline Previous myocardial infarction & 0.0 & $5255(36.5)$ & $7307(30.9)$ & $<.001$ \\
\hline Congestive heart failure & 0.0 & $3470(24.1)$ & $5111(21.6)$ & $<.001$ \\
\hline Unstable angina & 0.0 & $4676(32.4)$ & $6621(28.0)$ & $<.001$ \\
\hline Preoperative arrhythmia & 0.0 & $872(6.0)$ & $1396(5.9)$ & .036 \\
\hline NYHA class III or IV & 0.0 & $2561(17.8)$ & $3130(13.2)$ & $<.001$ \\
\hline LVEF of $<30 \%$ & 0.0 & $1178(8.2)$ & $978(4.1)$ & $<.001$ \\
\hline Preoperative IABP & 0.0 & $1852(12.8)$ & $2676(11.3)$ & $<.001$ \\
\hline Preoperative inotropic agents & 0.0 & $153(1.0)$ & $176(0.7)$ & .001 \\
\hline Left main disease $\geq 50 \%$ & 3.5 & $5879(40.8)$ & $9147(38.7)$ & $<.001$ \\
\hline Triple-vessel disease & 3.5 & $11,048(76.6)$ & $16,930(71.6)$ & $<.001$ \\
\hline Aortic stenosis grade $\geq 1$ & 0.0 & $477(3.3)$ & $812(3.4)$ & .387 \\
\hline Aortic insufficiency grade $\geq 2$ & 0.0 & $927(6.4)$ & $1994(8.4)$ & $<.001$ \\
\hline Mitral stenosis grade $\geq 1$ & 0.0 & $158(1.1)$ & $218(0.9)$ & .152 \\
\hline Mitral insufficiency grade $\geq 2$ & 0.0 & $2318(16.1)$ & $3944(16.7)$ & .109 \\
\hline Tricuspid insufficiency grade $\geq 2$ & 0.0 & 1095 (7.6) & $2222(9.4)$ & $<.001$ \\
\hline Steroids & 0.0 & $206(1.4)$ & 414 (1.8) & .009 \\
\hline Urgent status & 0.0 & 1676 (11.6) & 2259 (9.6) & $<.001$ \\
\hline
\end{tabular}

Data are presented as n (\%) or mean \pm SD. ONCAB, On-pump coronary artery bypass; OPCAB, off-pump coronary artery bypass; $e G F R$, estimated glomerular filtration rate; $P C I$, percutaneous coronary intervention; $N Y H A$, New York Heart Association; $L V E F$, left ventricular ejection fraction; IABP, intra-aortic balloon pump counterpulsation.

OPCAB than ONCAB group $(6.8 \%$ vs $10.3 \%$, respectively; $P<.001)$. The incidence of the composite outcome tended to rise as the preoperative renal function worsened. In all renal function strata except patients with normal renal function, the incidence of the composite outcome was significantly lower in the OPCAB group (Table 3). These results were confirmed in the multivariable logistic regression model as well as in the IPTW analyses (Table 4).

\section{DISCUSSION}

The mortality benefit of OPCAB has not been confirmed in previous randomized trials. ${ }^{4-6}$ However, most randomized trials that compared OPCAB versus ONCAB did not report the proportion of enrolled patients with preoperative renal disease. ${ }^{5}$ In addition, among the randomized trials that did report the proportion of patients with renal disease, the prevalence of chronic renal failure 
TABLE 2. Surgical data for overall cohort

\begin{tabular}{|c|c|c|c|}
\hline Variable & ONCAB $(n=14,417)$ & OPCAB $(n=23,634)$ & $P$ value \\
\hline Surgery duration, min & $354.7 \pm 102.9$ & $307.3 \pm 100.2$ & $<.001$ \\
\hline $\mathrm{CPB}$ time, $\min$ & $144.8 \pm 55.8$ & - & - \\
\hline Cardioplegia-arrested heart & $8190(56.8)$ & - & - \\
\hline Blood cardioplegia & $6372(77.8)$ & - & - \\
\hline Cold cardioplegia & $6390(78.0)$ & - & - \\
\hline Distal anastomoses, $\mathrm{n}$ & $3.17 \pm 1.11$ & $3.02 \pm 1.23$ & $<.001$ \\
\hline \multicolumn{4}{|l|}{ ITA use } \\
\hline Left & $13,605(94.4)$ & $22,375(94.7)$ & .108 \\
\hline Right & $4387(30.4)$ & $10,461(44.3)$ & $<.001$ \\
\hline Bilateral & $4081(28.3)$ & 9795 (41.4) & $<.001$ \\
\hline None & $500(3.5)$ & $594(2.5)$ & $<.001$ \\
\hline Missing & $6(0.0)$ & $0(0.0)$ & \\
\hline
\end{tabular}

Data are presented as $\mathrm{n}(\%)$ or mean $\pm \mathrm{SD}$. ONCAB, On-Pump coronary artery bypass; $O P C A B$, off-pump coronary artery bypass; $C P B$, cardiopulmonary bypass; ITA, internal thoracic artery.

was only $4.1 \% .^{5}$ Considering that renal function is an important risk factor in the reported risk models for $\mathrm{CABG},{ }^{1,2}$ this insufficient evaluation of preoperative renal function is a serious problem when interpreting the results of randomized trials. In this context, large retrospective studies focusing on preoperative renal function are still required to evaluate the clinical benefit of OPCAB. In the present study, we evaluated the association between the prognostic effect of OPCAB and preoperative renal function using a large data set from the JCVSD. The results showed that the risk reduction effect of OPCAB for surgical mortality was significant in patients with moderate or severe preoperative renal dysfunction.
First, the risk reduction effect of OPCAB for surgical mortality was significant in patients with moderate or severe preoperative renal dysfunction. This risk reduction effect of OPCAB was not shown in patients with normal renal function or mild preoperative renal dysfunction. This result is consistent with the findings reported by Chawla et al, ${ }^{15}$ who compared $\mathrm{OPCAB}$ versus $\mathrm{ONCAB}$ among various patient strata of preoperative renal function using a large data set $(\mathrm{n}=742,909)$ from the STS national database. In the propensity analysis, the authors reported that patients with CKD (eGFR $<90 \mathrm{~mL} / \mathrm{min} / 1.73 \mathrm{~m}^{2}$ ) experienced an associated mortality benefit of OPCAB but that patients with normal renal function did not (risk difference with

TABLE 3. Postoperative outcomes among various stages of renal disease

\begin{tabular}{|c|c|c|c|}
\hline Outcome & ONCAB $(n=14,417)$ & OPCAB $(n=23,634)$ & $P$ value \\
\hline Overall cohort & 14,417 & 23,634 & \\
\hline Surgical mortality & $354(2.5)$ & $344(1.5)$ & $<.001$ \\
\hline Newly required dialysis & $308(2.1)$ & $357(1.5)$ & $<.001$ \\
\hline Composite outcome & $1501(10.4)$ & $1600(6.8)$ & $<.001$ \\
\hline Mild renal disease (eGFR 60-90) & 2789 & 4471 & \\
\hline Surgical mortality & $34(1.2)$ & $30(0.7)$ & .015 \\
\hline Newly required dialysis & $16(0.6)$ & $22(0.5)$ & .639 \\
\hline Composite outcome & $182(6.5)$ & $193(4.3)$ & $<.001$ \\
\hline Moderate renal disease (eGFR 30-59) & 8620 & 14,107 & \\
\hline Surgical mortality & $133(1.5)$ & $131(0.9)$ & $<.001$ \\
\hline Newly required dialysis & $81(0.9)$ & $102(0.7)$ & $<.001$ \\
\hline Composite outcome & $726(8.4)$ & $749(5.3)$ & $<.001$ \\
\hline Severe renal disease $(\mathrm{eGFR}<30)$ & 1498 & 2600 & \\
\hline Surgical mortality & $82(5.5)$ & $72(2.8)$ & $<.001$ \\
\hline Newly required dialysis & $193(12.9)$ & $203(7.8)$ & $<.001$ \\
\hline Composite outcome & 339 (22.6) & $369(14.2)$ & $<.001$ \\
\hline Preoperative dialysis & 1510 & 2456 & \\
\hline Surgical mortality & $105(7.0)$ & $111(4.5)$ & .001 \\
\hline Composite outcome & $254(16.8)$ & $289(11.8)$ & $<.001$ \\
\hline
\end{tabular}

Data are presented as number (\%). eGFR is expressed in $\mathrm{mL} / \mathrm{min} / 1.73 \mathrm{~m}^{2} . O N C A B$, On-pump coronary artery bypass; $O P C A B$, off-pump coronary artery bypass; $e G F R$, estimated glomerular filtration rate. 
TABLE 4. Effect of off-pump technique on outcomes in patients with various stages of renal disease

\begin{tabular}{|c|c|c|c|}
\hline \multirow[b]{3}{*}{ Outcome } & \multicolumn{3}{|c|}{ OR $(95 \%$ CI $)$} \\
\hline & \multicolumn{3}{|c|}{ Risk-adjusted (multivariable } \\
\hline & Unadjusted & logistic regression) & IPTW \\
\hline \multicolumn{4}{|l|}{ Overall cohort } \\
\hline Surgical mortality & $0.59(0.51-0.68)^{*}$ & $0.65(0.56-0.76)^{*}$ & $0.66(0.56-0.77)^{*}$ \\
\hline Newly required dialysis & $0.70(0.60-0.82)^{*}$ & $0.76(0.65-0.89) \dagger$ & $0.75(0.64-0.88) \dagger$ \\
\hline Composite outcome & $0.62(0.58-0.67)^{*}$ & $0.67(0.62-0.72)^{*}$ & $0.67(0.62-0.73)^{*}$ \\
\hline \multicolumn{4}{|c|}{ Mild renal disease (eGFR 60-90) } \\
\hline Surgical mortality & $0.55(0.33-0.90) \ddagger$ & $0.68(0.40-1.14)$ & $0.67(0.41-1.11)$ \\
\hline Newly required dialysis & $0.86(0.45-1.63)$ & $1.22(0.62-2.41)$ & $1.15(0.59-2.21)$ \\
\hline Composite outcome & $0.65(0.52-0.80)^{*}$ & $0.73(0.59-0.91) \dagger$ & $0.73(0.59-0.90) \dagger$ \\
\hline \multicolumn{4}{|c|}{ Moderate renal disease (eGFR 30-59) } \\
\hline Surgical mortality & $0.60(0.47-0.76)^{*}$ & $0.64(0.50-0.83)^{*}$ & $0.66(0.51-0.84) \dagger$ \\
\hline Newly required dialysis & $0.77(0.57-1.03)$ & $0.83(0.61-1.13)$ & $0.84(0.62-1.14)$ \\
\hline Composite outcome & $0.61(0.55-0.68)^{*}$ & $0.65(0.58-0.72)^{*}$ & $0.66(0.59-0.73)^{*}$ \\
\hline \multicolumn{4}{|c|}{ Severe renal disease $(\mathrm{eGFR}<30)$} \\
\hline Surgical mortality & $0.49(0.36-0.68)^{*}$ & $0.51(0.36-0.73)^{*}$ & $0.51(0.37-0.72)^{*}$ \\
\hline Newly required dialysis & $0.57(0.46-0.71)^{*}$ & $0.62(0.49-0.77)^{*}$ & $0.61(0.49-0.75)^{*}$ \\
\hline Composite outcome & $0.57(0.48-0.67)^{*}$ & $0.59(0.50-0.71)^{*}$ & $0.59(0.50-0.70)^{*}$ \\
\hline \multicolumn{4}{|l|}{ Preoperative dialysis } \\
\hline Surgical mortality & $0.63(0.48-0.83) \dagger$ & $0.67(0.50-0.90) \dagger$ & $0.68(0.51-0.90) \dagger$ \\
\hline Composite outcome & $0.66(0.55-0.79)^{*}$ & $0.64(0.53-0.78)^{*}$ & $0.66(0.55-0.80)^{*}$ \\
\hline
\end{tabular}

eGFR is expressed in $\mathrm{mL} / \mathrm{min} / 1.73 \mathrm{~m}^{2}$. OR, Odds ratio; $C I$, confidence interval; $I P T W$, inverse probability of treatment weighting; $e G F R$, estimated glomerular filtration rate $* P<.001 . \dagger P<.01 . \ddagger P<.05$.

95\% confidence interval: eGFR of 60-89: 0.09, 0.02-0.17; eGFR of 30-59: 0.30, 0.12-0.47; and eGFR of 15-29: 1.92, 1.06-2.78). ${ }^{15}$ There are 2 major differences between the data from the national database of the United States and Japan. The first is the prevalence of renal dysfunction in patients who underwent CABG. In the report from the STS national database, $\mathrm{CKD}\left(\mathrm{eGFR}<60 \mathrm{~mL} / \mathrm{min} / 1.73 \mathrm{~m}^{2}\right)$ was present in $24.1 \%$ of the overall cohort. ${ }^{15}$ In the present study, however, $\mathrm{CKD}\left(\mathrm{eGFR}<60 \mathrm{~mL} / \mathrm{min} / 1.73 \mathrm{~m}^{2}\right)$ was present in as high as $79.4 \%$ of the overall cohort. In the report from the National Cardiovascular Data Registry Cath-PCI registry, CKD was present in $29.2 \%$ of the overall patients who underwent PCI in the United States, ${ }^{16}$ which is comparable with that of patients who underwent CABG (24.1\%). In contrast, the Japanese multicenter PCI registries reported that the prevalence of CKD in patients who underwent PCI was $28.3 \%$ to $38.5 \%,{ }^{17,18}$ which is comparable with that of patients in the United States and is extremely low compared with patients who underwent CABG in the present study. Therefore, the high prevalence of CKD in the present study cohort seems to have been affected by the differences in the coronary revascularization strategy (PCI/CABG ratio) between the 2 countries rather than the differences in the prevalence of CKD among different ethnic groups. The second is the frequency of OPCAB. In the report from the STS national database, $21.3 \%$ of patients were intended to undergo OPCAB. ${ }^{15}$ However, in the present study, up to $62.1 \%$ of patients were intended to undergo OPCAB. Despite these 2 large differences, the mortality benefit of OPCAB in patients with preoperative renal disease was confirmed in both of the studies from the United States and Japan. This seems to support the validity of the results in the present study. This mortality benefit of OPCAB, which has been shown in patients with preoperative renal disease, would explain why the previous randomized trials could not show the mortality benefit of OPCAB.

Second, the renoprotective effect of OPCAB was significant in patients with severe preoperative renal dysfunction. This is consistent with the previously mentioned study that analyzed data from the STS national database. ${ }^{15}$ In their propensity-weighted analysis, Chawla et $\mathrm{al}^{15}$ showed that the renoprotective effect of OPCAB was significant in patients with moderate or severe renal disease (risk difference per 100 patients with 95\% confidence interval: eGFR of 30-59: $0.47,0.31-0.62$; eGFR of 15-29: 2.79, 1.37-4.20). However, in their center-level analysis, the renoprotective effect of OPCAB was confirmed only in patients with severe renal disease. ${ }^{15}$ Other studies have also reported the renoprotective effect of OPCAB in patients with preoperative renal disease. ${ }^{19,20}$ In their study of patients with non-dialysis renal insufficiency (serum creatinine concentration of $>150 \mu \mathrm{mol} / \mathrm{L}$ ), Ascione et $\mathrm{al}^{19}$ reported that the postoperative serum creatinine concentration was significantly higher in the ONCAB than OPCAB group at 12 hours postoperatively and that the incidence of postoperative dialysis was higher in the ONCAB than OPCAB group $(15.8 \%$ vs $5.9 \%$, 
respectively; $P=.06$ ). Furthermore, Sajja et al ${ }^{20}$ performed the first randomized trial to compare OPCAB versus $\mathrm{ONCAB}$ in patients with non-dialysis renal insufficiency and reported worsening of renal function (serum creatinine concentration, glomerular filtration rate [GFR]) in the ONCAB than OPCAB group. In contrast, a meta-analysis of randomized trials did not show a risk reduction effect of OPCAB in patients with newly required dialysis. ${ }^{5}$ Moreover, some other studies have denied the renoprotective effect of OPCAB. ${ }^{21-23}$ In their casematched study of 5589 patients who underwent CABG, Elmistekawy et $\mathrm{al}^{21}$ showed that the requirements of postoperative newly required dialysis were equivalent at $2.6 \%$ in the OPCAB group and $2.1 \%$ in the ONCAB group. In a propensity score analysis of patients with preoperative renal dysfunction, Chukwuemeka et $\mathrm{al}^{22}$ reported that OPCAB was not associated with a reduced risk of renal dysfunction. In addition, a study of acute kidney injury after CABG in elderly patients did not show a renoprotective effect of OPCAB ${ }^{23}$ However, these studies might lack statistical power because of the limited number of enrolled patients with moderate or severe renal dysfunction. In the previously mentioned study using the STS national database, the risk difference of newly required dialysis per 100 patients was 0.47 in patients with moderate renal disease and 2.79 in patients with severe renal disease. ${ }^{15}$ This means that the "number needed to treat" was 213 patients with moderate renal disease and 36 patients with severe renal disease. The previously mentioned study by Elmistekawy et $\mathrm{al}^{21}$ included up to 1368 patients with moderate or severe renal dysfunction (GFR of 30-59, $\mathrm{n}=1244$ patients; GFR of $15-29, \mathrm{n}=124$ patients), but the number of patients who underwent OPCAB was limited because of the low frequency of OPCAB $(9.8 \%)$. Another study by Reents et $\mathrm{al}^{23}$ included only 299 patients with moderate or severe renal dysfunction in the OPCAB group (GFR of 30-59, $\mathrm{n}=268$; GFR of 15-29, $\mathrm{n}=31$ patients). The study by Chukwuemeka et al, ${ }^{22}$ which focused on patients with preoperative renal dysfunction, included only 146 patients in the OPCAB group. Considering the number needed to treat, enrollment of quite a large number of OPCAB patients with moderate or severe renal dysfunction is required to prove the renoprotective effect of OPCAB. This also explains why the renoprotective effect of OPCAB was not shown in previous randomized trials.

Consistent with the results of previous large randomized trials, ${ }^{10,11}$ fewer distal anastomoses were placed per patient who underwent OPCAB than ONCAB in the present study. Therefore, we performed an additional analysis on postoperative myocardial infarction. However, the risk of perioperative myocardial infarction was not higher in the OPCAB group as shown by the odds ratio (OPCAB vs ONCAB) for perioperative myocardial infarction with
$95 \%$ confidence interval: overall cohort $(0.7 \%$ vs $0.9 \%)$, $0.82(0.65-1.03)$; mild renal disease $(0.8 \%$ vs $0.8 \%)$, $1.02(0.59-1.76)$; moderate renal disease $(0.7 \%$ vs $1.1 \%)$, $0.67(0.51-0.90)$; severe renal disease $(0.5 \%$ vs $0.6 \%)$, $0.90(0.39-2.10)$; and preoperative dialysis $(0.8 \%$ vs $0.4 \%), 2.47(0.95-6.43)$ (estimated using the IPTW method). However, we could not estimate the long-term prognostic effect of fewer distal anastomoses in the OPCAB cohort because of the lack of long-term follow-up data in our database.

The present study has several limitations. First, because of the retrospective nature of this study, multivariable logistic regression and propensity score analysis could not completely adjust for potential selection bias. However, the confirmation of the clinical advantage of OPCAB using 2 different risk adjustment methods reinforces the validity of our results. Second, this study included only Japanese patients. Considering the differences in the prevalence of CKD among different ethnic groups, ${ }^{24}$ it is necessary to verify whether the findings of the present study can be applied to other ethnic groups. However, as mentioned previously, the report from the STS national database ${ }^{15}$ and the present study show similar results despite the large difference in the prevalence of CKD. Third, a relatively small number of adverse events occurred in patients with mild renal disease. This raises concern that the comparative analyses in this stratum might lack sufficient statistical power to detect the clinical effect of OPCAB. Therefore, we cannot make a definitive conclusion about the clinical benefit of OPCAB in patients with mild renal disease. Additionally, patients with CKD in the present study showed a high incidence of other preoperative risk factors such as diabetes mellitus (ONCAB, 55.9\%; OPCAB, $53.0 \%$ ), New York Heart Association class III or IV heart failure (ONCAB, 17.8\%; OPCAB, 13.2\%), and left main coronary artery disease (ONCAB, 40.8\%; OPCAB, $38.7 \%$ ). With this high-risk profile of the present cohort, the external validity of our findings for the general CABG population might be controversial. Finally, because of the lack of long-term data in the present study, our analysis of the clinical benefit of OPCAB is limited to short-term outcomes. Boulton et $\mathrm{al}^{25}$ reported that among patients with moderate to severe renal disease, long-term survival was worse in those who underwent OPCAB than ONCAB. The association between $\mathrm{OPCAB}$ and long-term survival in patients with preoperative renal dysfunction requires further study.

\section{CONCLUSIONS}

Among patients who undergo elective $\mathrm{CABG}$, OPCAB significantly reduces surgical mortality in patients with moderate or severe preoperative renal dysfunction. It is essential to consider the preoperative renal function of enrolled patients when interpreting the results of 
randomized trials that evaluated the risk reduction effect of OPCAB. Further comparison of OPCAB versus ONCAB with a particular focus on this high-risk patient cohort is needed.

\section{Webcast}

You can watch a Webcast of this AATS meeting presentation by going to: https://aats.blob.core.windows.net/ media/17AM/2017-05-01/RM311/05-01-17_Room311_1515_ Ueki.mp4.

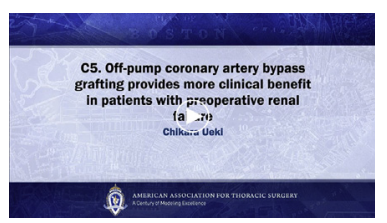

\section{Conflict of Interest Statement}

Authors have nothing to disclose with regard to commercial support.

The authors thank Hiroshi Tsuneyoshi for providing a video of OPCAB.

\section{References}

1. Miyata H, Tomotaki A, Motomura N, Takamoto S. Operative mortality and complication risk model for all major cardiovascular operations in Japan. Ann Thorac Surg. 2015;99:130-9.

2. Shahian DM, O'Brien SM, Filardo G, Ferraris VA, Haan CK, Rich JB, et al. The Society of Thoracic Surgeons 2008 cardiac surgery risk models: part 1-coronary artery bypass grafting surgery. Ann Thorac Surg. 2009;88:S2-22.

3. Cooper WA, O'Brien SM, Thourani VH, Guyton RA, Bridges CR, Szczech LA, et al. Impact of renal dysfunction on outcomes of coronary artery bypass surgery. Circulation. 2006;113:1063-70.

4. Kowalewski M, Pawliszak W, Malvindi PG, Bokszanski MP, Perlinski D, Raffa GM, et al. Off-pump coronary artery bypass grafting improves shortterm outcomes in high-risk patients compared with on-pump coronary artery bypass grafting: meta-analysis. J Thorac Cardiovasc Surg. 2016;151:60-77.

5. Deppe AC, Arbash W, Kuhn EW, Slottosch I, Scherner M, Liakopoulos OJ, et al. Current evidence of coronary artery bypass grafting off-pump versus on-pump: a systematic review with meta-analysis of over 16900 patients investigated in randomized controlled trials. Eur J Cardiothorac Surg. 2016;49:1031-41.

6. Møller CH, Penninga L, Wetterslev J, Steinbrüchel DA, Gluud C. Off-pump versus on-pump coronary artery bypass grafting for ischaemic heart disease. Cochrane Database Syst Rev. 2012;CD007224.

7. Puskas JD, Thourani VH, Kilgo P, Cooper W, Vassiliades T, Vega JD, et al. Off-pump coronary artery bypass disproportionately benefits high-risk patients. Ann Thorac Surg. 2009;88:1142-7.

8. Renner A, Zittermann A, Aboud A, Pühler T, Hakim-Meibodi K, Quester W, et al. Coronary revascularization in diabetic patients: off-pump versus on-pump surgery. Ann Thorac Surg. 2013;96:528-34.
9. Ueki C, Miyata H, Motomura N, Sakaguchi G, Akimoto T, Takamoto S. Off-pump versus on-pump coronary artery bypass grafting in patients with left ventricular dysfunction. J Thorac Cardiovasc Surg. 2016;151:1092-8.

10. Shroyer AL, Grover FL, Hattler B, Collins JF, McDonald GO, Kozora E, et al. On-pump versus off-pump coronary-artery bypass surgery. $N$ Engl J Med. 2009:361:1827-37.

11. Lamy A, Devereaux PJ, Prabhakaran D, Taggart DP, Hu S, Paolasso E, et al Off-pump or on-pump coronary-artery bypass grafting at 30 days. $N$ Engl $J$ Med. 2012;366:1489-97.

12. Masuda M, Kuwano H, Okumura M, Amano J, Arai H, Endo S, et al. Thoracic and cardiovascular surgery in Japan during 2012. Gen Thorac Cardiovasc Surg. 2014;62:734-64.

13. Matsuo S, Imai E, Horio M, Yasuda Y, Tomita K, Nitta K, et al. Revised equations for estimated GFR from serum creatinine in Japan. Am J Kidney Dis. 2009;53: 982-92.

14. Curtis LH, Hammill BG, Eisenstein EL, Kramer JM, Anstrom KJ Using inverse probability-weighted estimators in comparative effectiveness analyses with observational databases. Med Care. 2007;45(Suppl 2):S103-7.

15. Chawla LS, Zhao Y, Lough FC, Schroeder E, Seneff MG, Brennan JM. Off-pump versus on-pump coronary artery bypass grafting outcomes stratified by preoperative renal function. J Am Soc Nephrol. 2012;23:1389-97.

16. Tsai TT, Patel UD, Chang TI, Kennedy KF, Masoudi FA, Matheny ME, et al. Contemporary incidence, predictors, and outcomes of acute kidney injury in patients undergoing percutaneous coronary interventions: insights from the NCDR Cath-PCI registry. JACC Cardiovasc Interv. 2014;7:1-9.

17. Furukawa Y, Ehara N, Taniguchi R, Haruna Y, Ozasa N, Saito N, et al. Coronary risk factor profile and prognostic factors for young Japanese patients undergoing coronary revascularization. Circ J. 2009;73:1459-65.

18. Sawano M, Kohsaka S, Abe T, Inohara T, Maekawa Y, Ueda I, et al. Patterns of statin non-prescription in patients with established coronary artery disease: a report from a contemporary multicenter Japanese PCI registry. PLoS One 2017;12:e0182687.

19. Ascione R, Nason G, Al-Ruzzeh S, Ko C, Ciulli F, Angelini GD. Coronary revascularization with or without cardiopulmonary bypass in patients with preoperative nondialysis-dependent renal insufficiency. Ann Thorac Surg. 2001;72:2020-5.

20. Sajja LR, Mannam G, Chakravarthi RM, Sompalli S, Naidu SK, Somaraju B, et al. Coronary artery bypass grafting with or without cardiopulmonary bypass in patients with preoperative non-dialysis dependent renal insufficiency: a randomized study. J Thorac Cardiovasc Surg. 2007;133:378-88.

21. Elmistekawy E, Chan V, Bourke ME, Dupuis JY, Rubens FD, Mesana TG, et al Off-pump coronary artery bypass grafting does not preserve renal function better than on-pump coronary artery bypass grafting: results of a case-matched study. $J$ Thorac Cardiovasc Surg. 2012;143:85-92.

22. Chukwuemeka A, Weisel A, Maganti M, Nette AF, Wijeysundera DN, Beattie WS, et al. Renal dysfunction in high-risk patients after on-pump and off-pump coronary artery bypass surgery: a propensity score analysis. Ann Thorac Surg. 2005;80:2148-53.

23. Reents W, Hilker M, Börgermann J, Albert M, Plötze K, Zacher M, et al. Acute kidney injury after on-pump or off-pump coronary artery bypass grafting in elderly patients. Ann Thorac Surg. 2014;98:9-15.

24. Zhang QL, Rothenbacher D. Prevalence of chronic kidney disease in population-based studies: systematic review. BMC Public Health. 2008;8:117.

25. Boulton BJ, Kilgo P, Guyton RA, Puskas JD, Lattouf OM, Chen EP, et al Impact of preoperative renal dysfunction in patients undergoing off-pump versus on-pump coronary artery bypass. Ann Thorac Surg. 2011;92:595-602.

Key Words: off-pump coronary artery bypass grafting, operative mortality, preoperative renal function 